\title{
Reaching the lower stratosphere: validating an extended vertical grid for COSMO
}

\author{
J. Eckstein, S. Schmitz, and R. Ruhnke \\ Karlsruhe Institute of Technology, Institute of Meteorology and Climate Research, \\ Herrmann-von-Helmholtz-Platz 1, 76344 Eggenstein-Leopoldshafen, Germany \\ Correspondence to: J. Eckstein (johannes.eckstein@kit.edu)
}

Received: 25 November 2014 - Published in Geosci. Model Dev. Discuss.: 26 January 2015

Revised: 6 May 2015 - Accepted: 1 June 2015 - Published: 23 June 2015

\begin{abstract}
This study presents an extended vertical grid for the regional atmospheric model COSMO (COnsortium for Small-scale MOdeling) reaching up to $33 \mathrm{~km}$. The extended setup has been used to stably simulate 11 months in a domain covering central and northern Europe. Temperature and relative humidity have been validated using radiosonde data in polar and temperate latitudes, focussing on the polar and mid-latitude stratosphere over Europe. Temperature values are reproduced very well by the model. Relative humidity could only be met in the mean over the whole time period after excluding data from Russian stations, which showed significantly higher values. A sensitivity study shows the stability of the model against different forcing intervals and damping layer heights.
\end{abstract}

\section{Introduction}

The upper troposphere and lowermost stratosphere is a place of sharp gradients in many constituents of air and of the physical parameters used to describe its state. Temperature and ozone are textbook examples, but methane, water and many more species also show a strong gradient. At the same time, being the boundary to the lower atmosphere, this is an area where small-scale fluctuations can have a strong influence on the stratosphere and its composition (Zahn et al., 2014).

In order to simulate this highly vulnerable and influential layer directly, a model with high vertical and horizontal resolution is needed. Global models usually are too coarsely resolved and cannot model the small-scale processes. In extending the vertical layering of the regional model COSMO (COnsortium for Small-scale MOdeling) to
$33 \mathrm{~km}$, we present here a model that can fill the gap. As we planned to apply the extended setup to simulations covering polar spring and the associated ozone loss with the coupled chemistry model COSMO-ART (COSMO-Aerosols and Reactive Trace gases) (Vogel et al., 2009), we focus here on polar latitudes, but always refer to temperate regions also.

After an introduction to the model and an exact definition of the extended vertical grid in Sect. 2, the measurement data are introduced in Sect. 3. COSMO is shown to be able to run stably with the extended layering. Using radiosonde data and regridded data from meteorological reanalyses, it is shown that the model is able to reproduce temperatures very well (Sect. 4.2) while relative humidity is more difficult (Sect. 4.3) and only its mean value could be reproduced. Two runs with different boundary conditions were performed to test the influence on the model result.

Additionally, three more runs were done in order to test the stability of the model against an increased boundary forcing interval set to 12 and $24 \mathrm{~h}$ instead of $6 \mathrm{~h}$ and against increasing the thickness of the damping layer by setting its lower end down to $22 \mathrm{~km}$ instead of $28 \mathrm{~km}$. Section 5 presents the results of this sensitivity study, showing that the model will still run stably.

\section{The model: vertical grid, boundary data and domain}

This section gives a short introduction to COSMO and explains the changes made to the standard vertical grid as well as the boundary data used and the specified domain. 


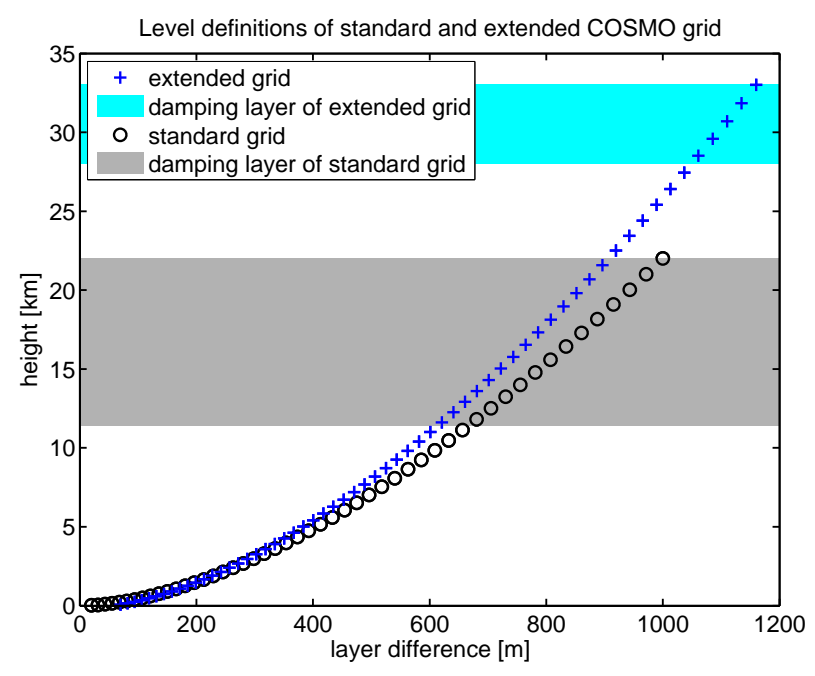

Figure 1. The vertical grids of the COSMO model considered in this study. The damping layers are also given as shaded areas.

\subsection{Introduction to the model}

COSMO is a regional atmospheric model that has been developed by a consortium lead by the german weather service DWD (German Weather Service). DWD uses the model for its regional numerical weather forecast of Europe and Germany with a resolution of 7 and $2.8 \mathrm{~km}$ respectively (Baldauf et al., 2011b). Many extensions have been developed for the model, for example COSMO-ART including chemistry and aerosols (Vogel et al., 2009). For this study, the model was set up to run in forecast mode to simulate several months in form of a hindcast using reanalysis data as boundary forcing.

The standard setup of COSMO used for the forecast of central Europe (DWD domain COSMO-DE) reaches to a height of $22.0 \mathrm{~km}$ (Baldauf et al., 2011a). This is the vertical grid referred to as the standard vertical setup or grid in this study, well aware of the fact the vertical grid used to simulate a larger European domain (COSMO-EU) that reaches up to $23.6 \mathrm{~km}$ (Schulz and Schättler, 2009) is just as frequently used by DWD. The model has also been used to study greater heights in tropical latitudes in the AMMA (African Monsoon Multidisciplinary Analyses) project (Gantner and Kalthoff, 2010), reaching $28.0 \mathrm{~km}$, and a tropical setup reaching up to $30.0 \mathrm{~km}$ has also been developed (Krähenmann et al., 2013). With the extended vertical grid presented in this study, it becomes possible to simulate the lowermost stratosphere in polar latitudes. This validation study opens the door to new applications of COSMO.

\subsection{The extended vertical grid}

The standard vertical grid of the COSMO model reaches up to $22.0 \mathrm{~km}$ in 50 layers. The vertical structure is visible in Fig. 1, exact values are given in Table A1. The damping layer in the top layers begins at $11357 \mathrm{~m}$ in standard setup.

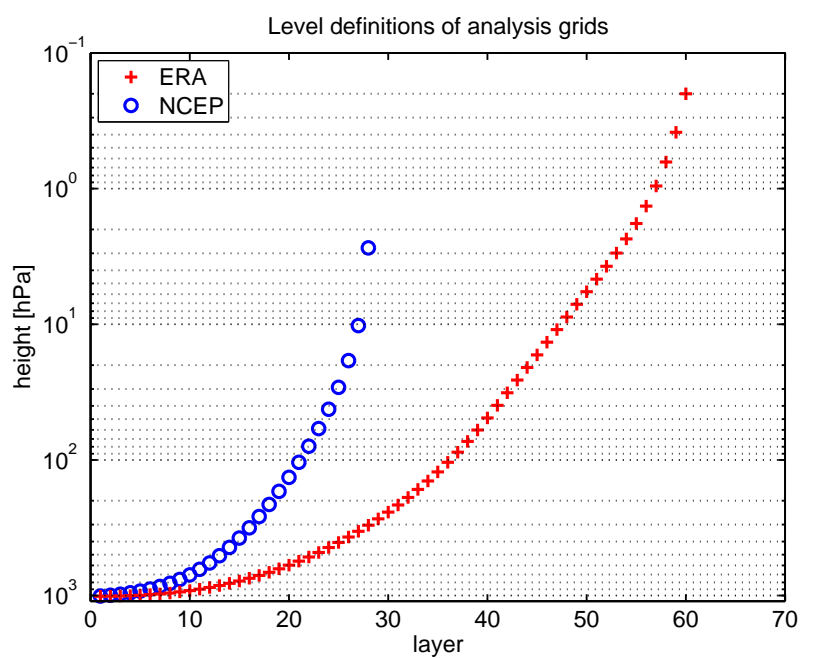

Figure 2. The vertical structure of the NCEP and ERA-Interim reanalysis used as boundary conditions.

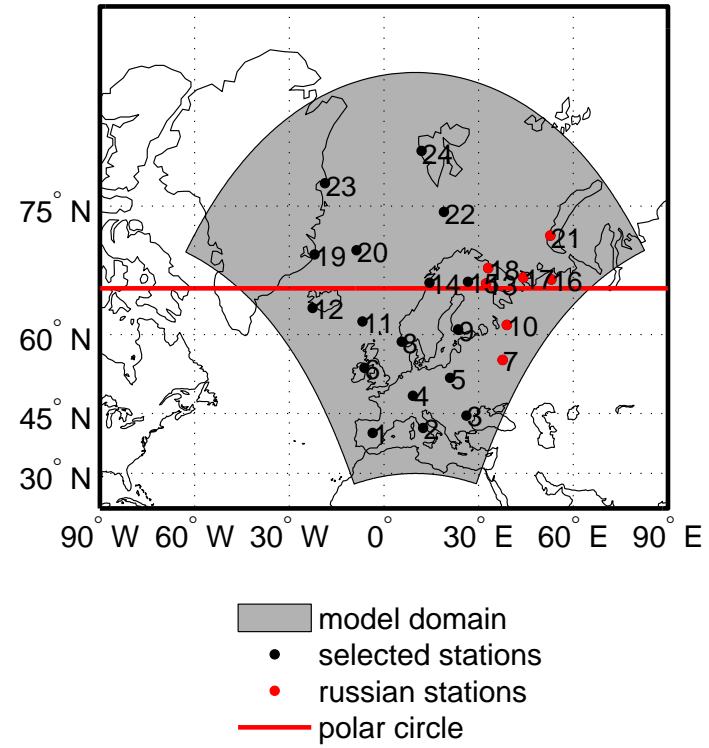

Figure 3. The model domain and the radiosonde stations used in this study. The domain is displayed as gray shading, the radiosonde stations are numbered from south to north, numbers also referring to Table B1. Russian stations are marked in red.

The vertical layering of the new grid introduced in this study is also given in Fig. 1 and Table A1. It is focused on the lower stratosphere, with the highest of the 60 layers at $33 \mathrm{~km}$, the damping layer beginning at $28 \mathrm{~km}$ (rdheight $=28000.0$ in the namelist). The top layer of the extended grid about $10 \mathrm{~km}$ above that of the standard grid and the distance between the layers is slightly smaller in all heights above the lowest kilometer, as is also visible in Fig. 1.

In order to test the sensitivity of the model to the size of the damping layer, an additional model run was done, for which the lower boundary of the damping layer was set to $22 \mathrm{~km}$ 

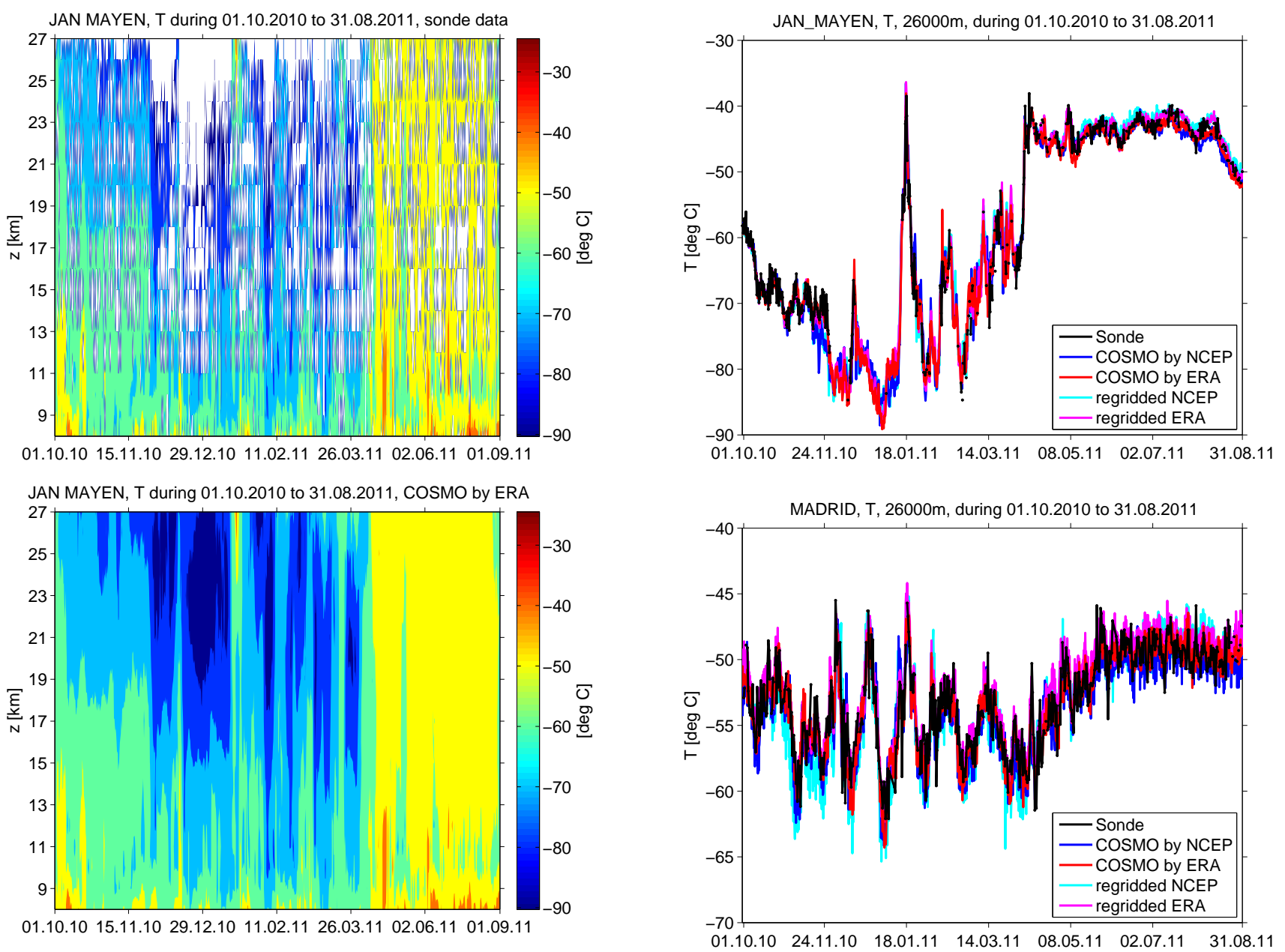

Figure 4. Temperature values of all soundings of the station Jan Mayen, station no. 20. Measurements are displayed on the top, the image below shows the corresponding model values. Note that this is not a time series plot. The dates along the abscissa hold true only for the location they indicate and do not define exact time in between. Dates only increase from left to right, but they are not evenly spaced in time.

(rdheight $=22000.0$ in the namelist), which is just the top of the standard grid. The damping layer then spans one-third of the model layers.

\subsection{The analyses used as boundary data}

In order to examine the influence of different boundary data on the model results, the model was run twice, using ERAInterim and NCEP (National Center for Environmental Prediction) reanalysis data for starting and boundary values. The vertical layering of the two reanalyses is displayed in Fig. 2. In order to better evaluate the model, the reanalysis data were also interpolated to the vertical grid used for the output of the model.

The reanalysis project of the National Center for Environmental Prediction provides data starting on 1 January 1948, 
ing it as forcing every 12 and $24 \mathrm{~h}$ (hincbound $=12.0$ or hincbound $=24.0$ respectively).

\subsection{The model domain}

The model domain used in this study is shown in Fig. 3. It covers most of Europe with a focus on the polar latitudes, stretching from northern Africa in the south and covering Svalbard, east of Greenland at $74^{\circ} \mathrm{N}$, in the north. The resolution was set to $0.2^{\circ}$. The COSMO model is operationally used by DWD to produce regional weather forecasts for central Europe, but not in Northern Hemisphere polar latitudes (Baldauf et al., 2011a).

So the domain chosen here can be used to assess the performance of the model in polar latitudes, since a direct comparison to an area of regular use is possible. The required namelist parameters needed to reproduce the model domain are given in Table A2.

The first time step simulated by the model runs used in this study is 1 October 2010, 00:00 UTC, and the last output is for 1 September 2011, 00:00 UTC. The cold temperatures that can be expected in the polar stratosphere especially in winter and the warming in spring both lay well within the simulated time. Output was produced on an hourly basis, the model time step was set to $60 \mathrm{~s}$, using the namelist parameter $\mathrm{dt}=60.0$. It could be shown that the model runs stably in this setup by validating the whole time period with radiosonde data.

The timespan of 11 months is due to the time limit applied to the calculation. The model was run with a time limit of 2 days, reaching a total number of 8076 output hours. The last output then turns out to be on 2 September 2011, at 11:00 UTC, but the authors decided to perform this study for the exact 11 months, as given above.

\section{Measurements}

This study validates the output of the COSMO model using the temperature $(T)$ and relative humidity $(\mathrm{RH})$ recorded by radiosondes of stations within the model domain. $T$ and $\mathrm{RH}$ are regularly observed values and are here considered basic physical parameters whose distribution well represents the physical state of the model. The measurement data used in this study were taken from the ESRL (Earth System Research Laboratory) radiosonde database provided by NOAA (National Oceanic and Atmospheric Administration) (Schwartz and Govett, 1992).

The location of the 24 stations is given in Fig. 3, exact values and the names being given in Table B1. This choice includes all polar stations in the domain and the same number of temperate stations with good data coverage.

All stations typically release one radiosonde every $12 \mathrm{~h}$, at 00:00 and 12:00 UTC, so 671 ascents can be expected from each station during the period of 335 simulated days. The actual number of ascents for each station is also given in Table B1. All stations except Ny-Ålesund, which has a little more than one ascent per day, come close to or exceed this number, the average being at 673 ascents. Model and regridded reanalysis data were only considered at times when there was an ascent at the specific station, so approximately every $12 \mathrm{~h}$.

In order to compare sonde and model data, the grid point closest to each station was used to compare the simulation with measurements. Since the resolution is only $0.2^{\circ}$, the error made by this simple identification is small. The latitude and longitude of the closest grid point can also be found in Table B1. An interpolation to the exact location was not considered necessary as the radiosondes drift with the wind, an effect not accountable, since the exact geographic location of each measurement taken by the sonde is not available. This is also the reason why no interpolation in the vertical was done.

In each ascent, the value closest to each model output layer at even kilometers was identified with the height of that layer, the maximum difference allowed having been set to $500 \mathrm{~m}$. Since there are typically more than 20 measurements taken in an ascent, the error was much smaller than this value, reaching only $156.0 \mathrm{~m}$ on average, with a standard deviation of $126.3 \mathrm{~m}$.

The data were used as downloaded from the server, only excluding values in $\mathrm{RH}>100 \%$. It was found that all stations in Russia give much higher humidity values than the other stations, which is the reason why the humidity data of all Russian stations were excluded from the investigation. This will be further discussed in Sect. 4.3.1.

\section{Results}

This sections presents the results of the model validation study. Two questions are to be answered: is the model able to simulate the polar latitudes and the stratospheric heights? And what is the influence of the boundary data on these results? Following the questions, the answers will also have to be twofold.

After presenting the output grid, the results in temperature are presented. Those of relative humidity are described in the following section. The latter is preceded by the explanation of why it seemed reasonable to exclude the data of Russian stations when examining relative humidity.

\subsection{The output grid}

In order to compare the model results to the measurements, model output on a vertical grid of whole kilometers from 8 to $33 \mathrm{~km}$ was used. The values given out above $27 \mathrm{~km}$ are already within the damping layer and the results can no longer be considered to come genuinely from the model, so measurements were only compared up to $27 \mathrm{~km}$. 

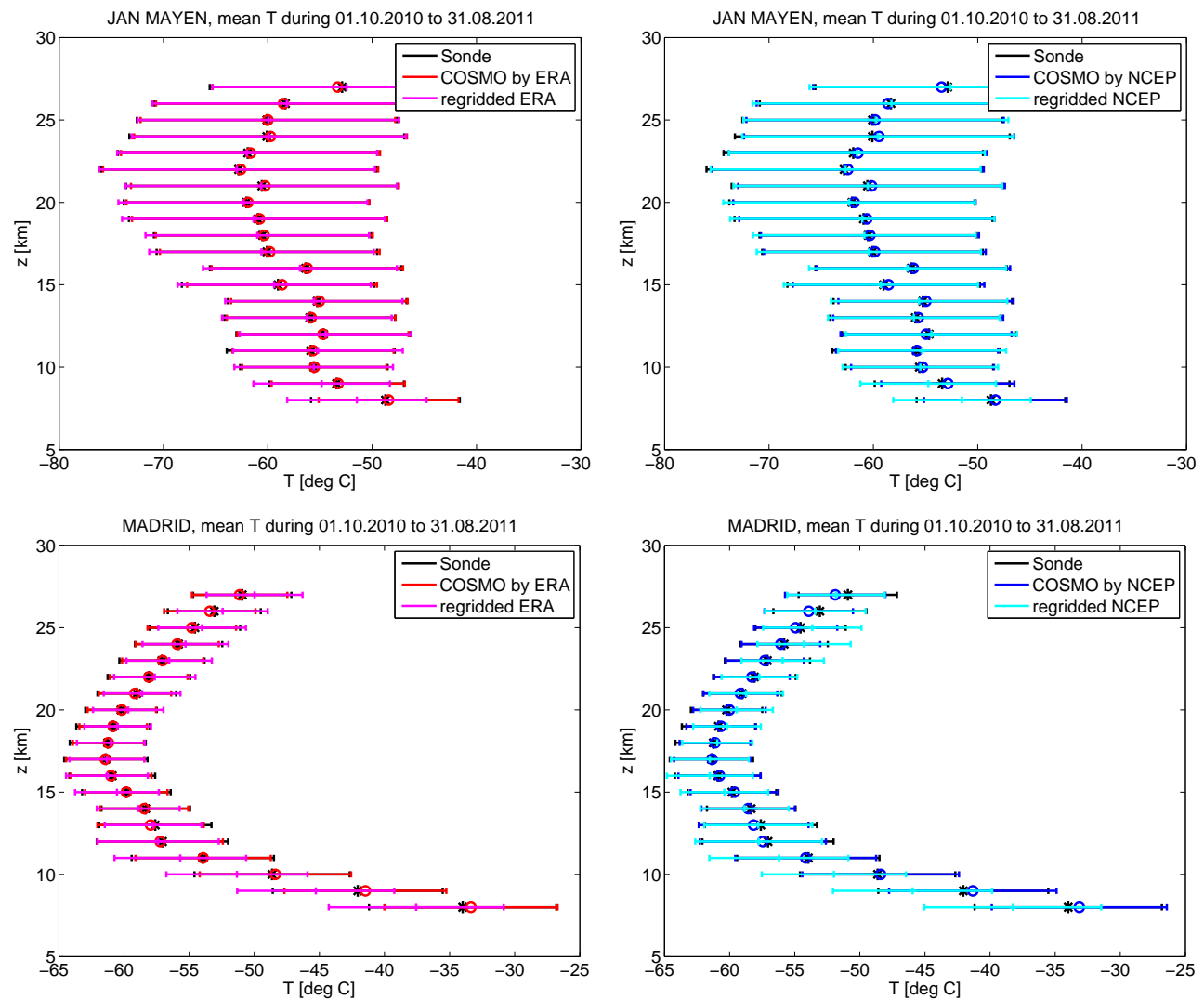

Figure 6. Mean temperature values at each height for the station on Jan Mayen, station no. 20, on the top, and for Madrid, station no. 1, on the bottom, showing results of the run forced by ERA-Interim (left) and NCEP (right). The horizontal lines give the $1 \sigma$ standard deviation.

As noted above, the boundary data were also interpolated onto the output grid, using the same program that is used to prepare the boundary data for running the model, called INT2LM (Schättler, 2013). COSMO uses terrain following coordinates. Above a certain value specified in the namelist, the layers become smooth and are no longer terrain following. This height has to be higher than the highest mountain tops in the domain and in this case was set to vcflat $=7000.0$, given in the namelist in meters. This is the reason why all analyses done in this study only start at $8 \mathrm{~km}$.

\subsection{Temperature}

To begin the discussion, a look at Fig. 4 exemplifies the basis of this study. It shows all the soundings of the station Jan Mayen during the time considered here. The warming at the end of the polar winter can be plainly seen. Most striking are the many white areas in the image, showing the lack of measurement data. The bottom figure shows the corresponding result of the model run with boundary data by ERA-Interim. The image is filled, but the data were only used for the following analysis if measurements were also available at the timestamp.
Figure 5 gives exemplary time series of Jan Mayen and Madrid at $26 \mathrm{~km}$ height, approximately $2.5 \mathrm{~km}$ above the model top of the standard vertical COSMO grid for both model runs. When comparing the two figures, temperature values reflect the different latitude: winter temperatures above Jan Mayen are much colder than above Madrid, the warming in spring much more pronounced. The good correspondence of model and measurement not only shows that the two model runs and also the boundary data are very similar, but also that the model performance does not change during the whole simulated period. There is no greater offset in the end than in the beginning.

To compare the data in a more quantitative manner, Fig. 6 shows the mean ascent at Jan Mayen for both model runs. The boundary data are also included in the image. All three soundings lay on top of each other. The minimum temperature in the lowermost stratosphere is well reproduced. In order to compare to a temperate station, Fig. 6 also gives the mean ascent of the station in Madrid. The minimum is more pronounced, but also reproduced by the model. There is no difference visible between the model run forced by ERAInterim and that forced by NCEP reanalysis data.

In order to further compare the performance of COSMO, Fig. 7 shows the scatterplots of all measured against mod- 

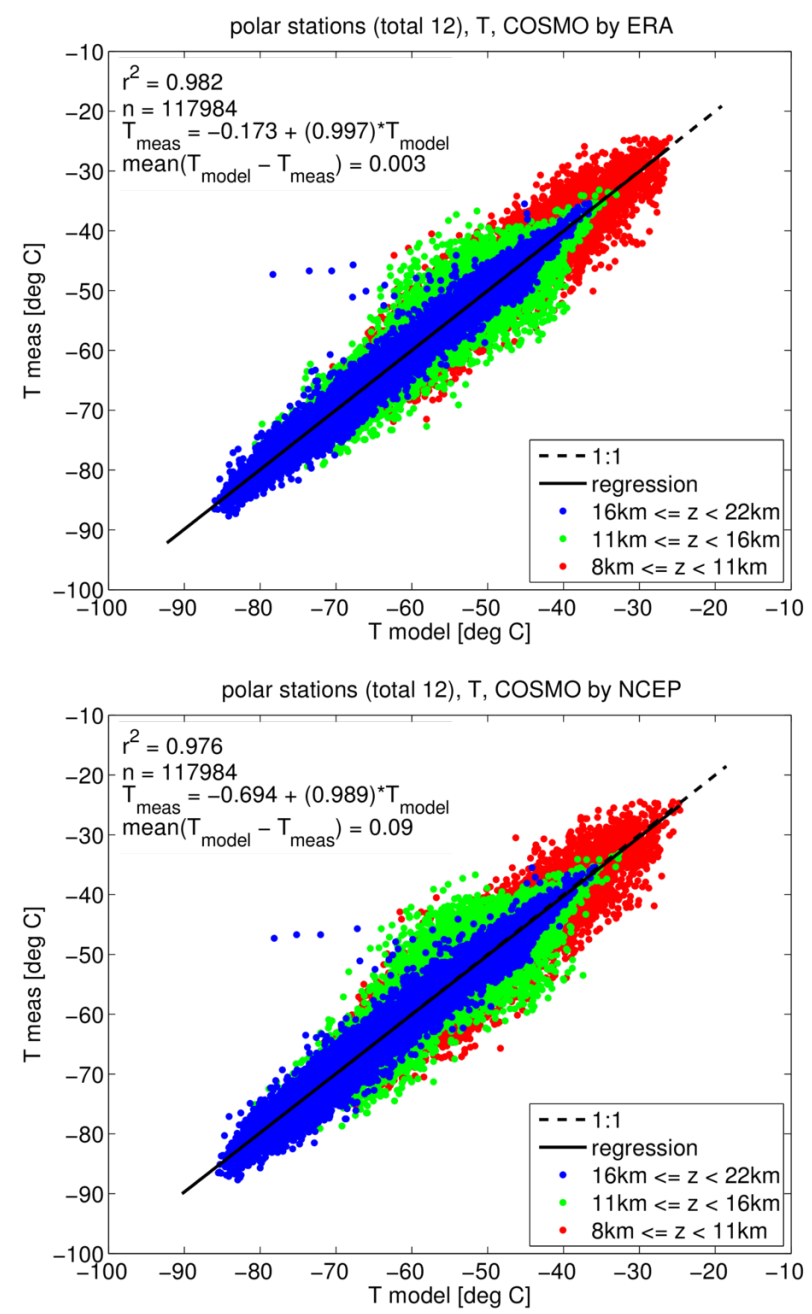

Figure 7. Scatterplot of modeled against measured temperature for polar stations when forcing the model with ERA-Interim (top) and NCEP reanalysis data (bottom). The data were color coded by height to visually inspect the variability in each height section. The statistics in the upper left hand corner refer to the whole data set.

eled temperature values with color coded height intervals for all polar stations. The variability in higher altitudes is lower, which is why the scatter is reduced with height. Both model runs with different boundary data simulate temperature very well, reaching about $r^{2}=0.98$. The results of the model in temperate latitudes was just as good and the correlation does not reach higher values when using the regridded boundary data (not shown).

When reducing the data to values of descriptive statistics, all stations can be easily compared. Figure 8 shows the mean of $T_{\text {model }}-T_{\text {meas }}$ and $T_{\text {bound }}-T_{\text {meas }}$ for all levels and for stratospheric levels with $z \geq 11 \mathrm{~km}$. The stratospheric layers are also those layers added when using the extended instead of the standard vertical grid. In both cases, the values are well reproduced by the model. When considering all layers, the mean values of the boundary data are lower than those of
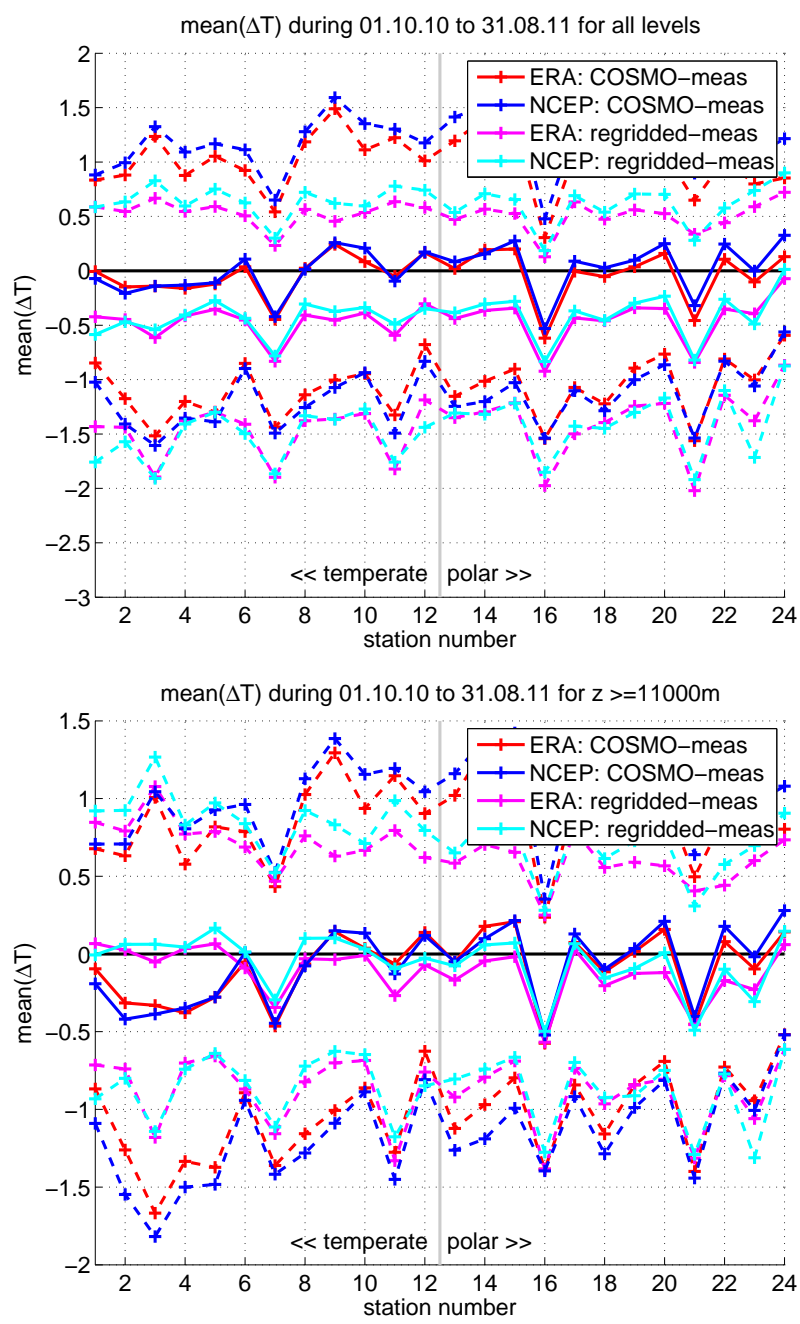

Figure 8. Mean difference in temperature over all heights (top) and heights with $z \geq 11 \mathrm{~km}$ (bottom) for each station. The dashed line corresponds in color to the full line which is always half the standard deviation of the difference above and below the mean value. See Table B1 for a list of the stations corresponding to the numbers.

measurement, the model output actually being closer to the measurement. When considering the new stratospheric layers, the model performance is just as good as it is when considering all layers. The boundary data are now closer to measurements than for all levels. Overall, COSMO is able to reproduce measurements in temperate as well as polar latitudes in all heights, the mean difference never exceeding $0.5 \mathrm{~K}$.

The spatial distribution for the run forced by ERA-Interim is shown in Fig. 9, the figure being very similar when looking at the results of the run using the NCEP reanalysis as boundary data. It now becomes clear that the slight outliers of stations 7, 16 and 21 also visible in Fig. 8 are all close to the eastern border of the model domain. By looking at the stations used to examine the problem of Russian humidity data, however, it could be shown that this effect is not visible when considering more eastern stations. It is not due to 
Meas-COSMO by ERA, 01.10 .10 to 31.08 .11 , all levels
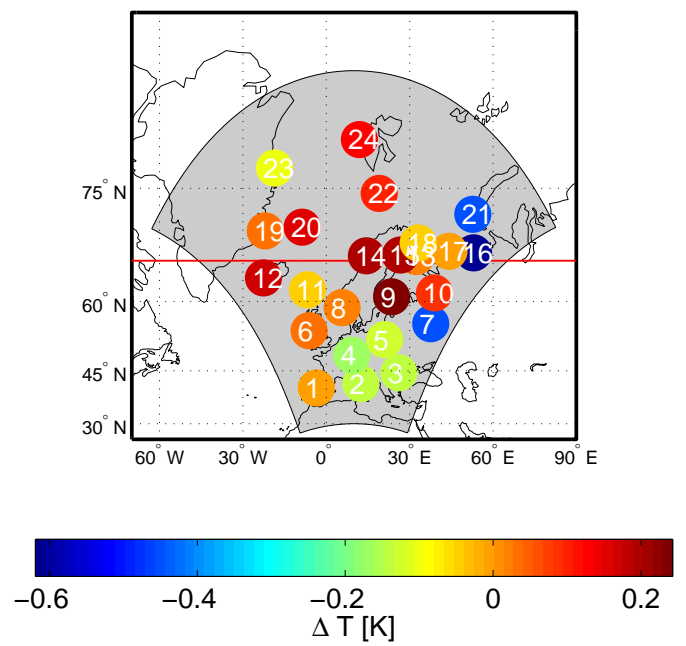

Figure 9. Mean difference of model values and measurements of temperature for each station over all levels when using ERA-Interim as forcing data. The picture is similar when using NCEP reanalysis data.

the relative location of the three stations within the model domain but more likely to the measurement data.

Another aspect when comparing the model output to measurements and regridded reanalysis data are the variability of the model in between those times when measurements or reanalysis data are available. Model output was saved every hour, while measurement or reanalysis data are available at most every $6 \mathrm{~h}$, as explained in Sects. 2.3 and 3. In order to asses this variability, Fig. 10 shows a shorter time series of only 10 days of the three data sets, including all existing model and reanalysis data. It becomes obvious that the model shows an internal variability that is not present in the less frequent measurement or reanalysis data. The greater variability is linked to physical processes that happen on short timescales of only hours or less. These cannot be captured by regridding the reanalysis data to a finer grid.

\subsection{Relative humidity}

\subsubsection{Excluding the Russian humidity data}

When examining the relative humidity of the 24 stations chosen for the validation of the model, it became apparent that the model could not reproduce the relative humidity data of any station within Russia (or of Gomel, the only station in Belarus with data during the modeled period, as became clear when examining more stations).

As there was no apparent reason for this offset and only seven stations lay within Russia in the original set (five polar and two temperate), this issue needed further investigation. The data of all available 23 Russian stations well within the model domain and Gomel in Belarus (see Table B2) were
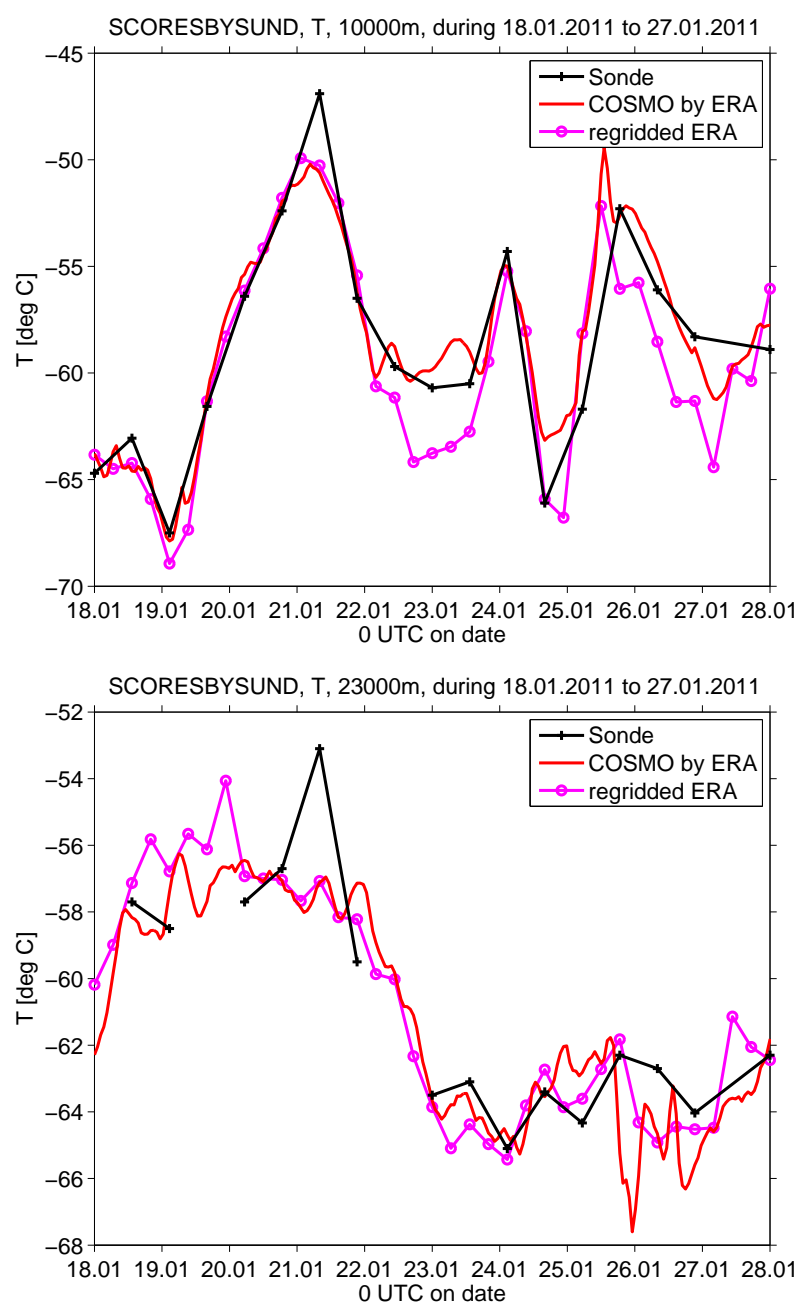

Figure 10. Time series of measured and modeled temperature as well as the regridded boundary data, 10 (top) and $23 \mathrm{~km}$ (bottom) above Scoresbysund, station no. 19, over 10 days at the end of January 2011. All data points available in each data set are included.

compared with 24 other stations in the eastern part of the domain but not in Russia or Belarus (see Table B3). The result is best illustrated by the mean over all RH values of all ascents in each group. Figure 11 shows the result for the Russian stations and the 24 stations outside of Russia that had been chosen. While the model reproduces the values of the stations outside of Russia, the measurement values of those stations within Russia are very different from the model values but also from the regridded analysis or the measurements of those stations outside of Russia.

In addition to the mean, the station Kaliningrad (no. 8), surrounded by the non-Russian stations Leba (no. 11), Kaunas (no. 12), Visby (no. 13) and Tallinn (no. 16) also allows for a spatial investigation. While the results of Kaliningrad are similar to the mean of Russian stations, the mean ascents of the surrounding stations are all similar to the mean of the non-Russian stations. 


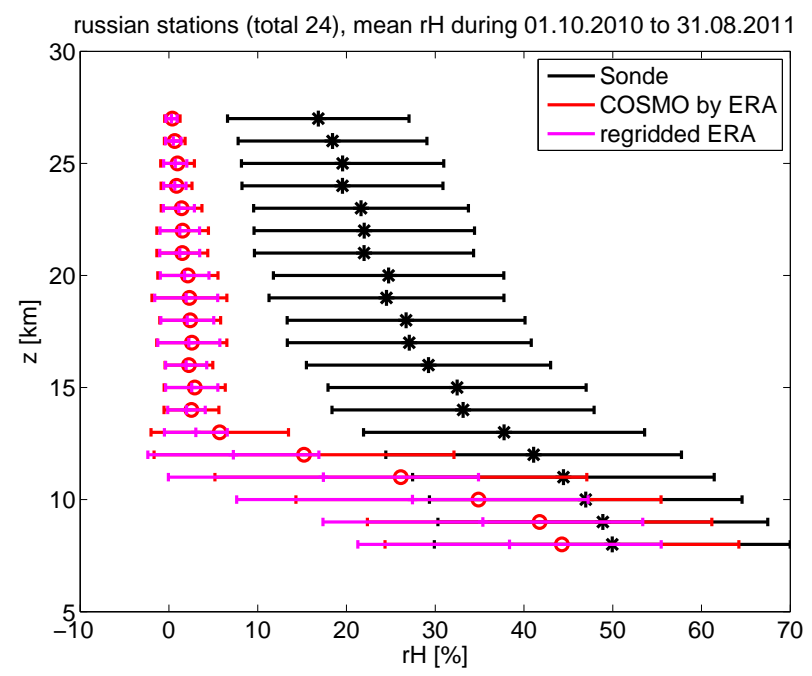

nonrussian stations (total 24), mean $\mathrm{rH}$ during 01.10 .2010 to 31.08 .2011

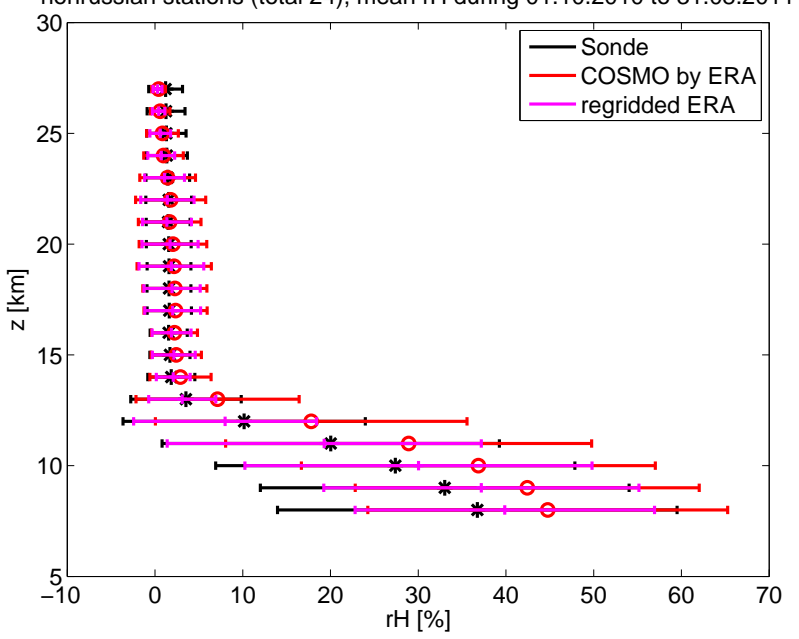

Figure 11. Mean relative humidity values of Gomel (BY) and the 23 Russian stations (top), and 24 stations outside of Russia but in the eastern part of the domain (bottom). The horizontal lines give the $1 \sigma$ standard deviation.

These two findings are in line with Balagurov et al. (2006) and Moradi et al. (2013). The authors of these studies come to the conclusion that the measurement technique used in radiosondes of Russia give values for relative humidity that are significantly too high for low pressure. All together, this lead to the decision to exclude Russian stations from the further investigation of the performance of COSMO with respect to relative humidity.

\subsubsection{Results when excluding Russian data}

When excluding the Russian stations (no. 7, 10, 13, 16-18 and 21), 10 temperate and 7 polar stations remain to examine relative humidity.

The mean values of the ascents of temperate and polar stations for both model runs is given in Fig. 12. The low strato- spheric values are well reproduced by the model for polar and temperate stations and both runs, while the tropospheric offset is larger. In heights lower than $13 \mathrm{~km}$, the model is too humid on average, the values being approximately $10 \%$ too high. The mean of tropospheric values seems to be better reproduced for polar stations when using the NCEP reanalysis. The bias is of measurements and model data are also present in the forcing reanalysis data, these being dryer than measurements on average. The model reduces this bias and produces a wetter atmosphere than that of the reanalyses. So the bias is combination of model physics, boundary data and maybe also measurement problems. Overall, model results fit measurements better than the reanalysis data.

However, when looking at the scatterplot of the polar stations, given in Fig. 13, it becomes clear that the model is only able to reproduce a mean value that is similar to the measurements. There is no notable correlation in any height. The variability in the measurements is simply too high to be reproduced by the model. This is also visible in the figures showing the mean ascents. The standard deviation of the model and the regridded analysis is much smaller than that of the measurements in stratospheric layers. Figure 14 shows the time series of relative humidity at 10 and $21 \mathrm{~km}$ heights. At $21 \mathrm{~km}$ height, the values are very low most of the time. While the small-scale variations in the troposphere are not reproduced by the model, the stratospheric variability is well captured by the model.

Figure 15 shows the spatial distribution of mean $\mathrm{RH}_{\text {meas }}-$ $\mathrm{RH}_{\text {model }}$ over all layers. The Russian stations have been excluded, but two other stations also show an offset compared to the other stations: Tórshavnar (no. 11) and Scoresbysund (no. 23). The modeled values are higher than measurements, with $\Delta \mathrm{RH}=4 \%$. This again is probably not an effect of the model but more likely of the measurements since surrounding stations do not show similar effects. The value fits the range of 2-6\% of dry bias reported by Wang et al. (2013) for radiosondes of type Vaisala RS92, but the type of sonde is not known for any of the stations in this study.

Relative humidity is on the one side very variable, so that it becomes hard to model exactly, and on the other side it seems not an easy parameter to measure, as the problems first found in Russian data show which are apparently also present in the data of other stations.

Similar to examining temperature, a closer look at a shorter time period in form of a time series can give information on the internal variability of relative humidity in the model. Figure 16 shows the time series of relative humidity at Scoresbysund for 10 days at the end of January 2011. The model shows a great variability on short timescales that is not present in the other data sets. The coarsely time-resolved measurements cannot be used to judge the fluctuations happening in the model on short timescales. It becomes understandable that especially relative humidity is difficult to compare to radiosonde data, as the variability in the field is just 

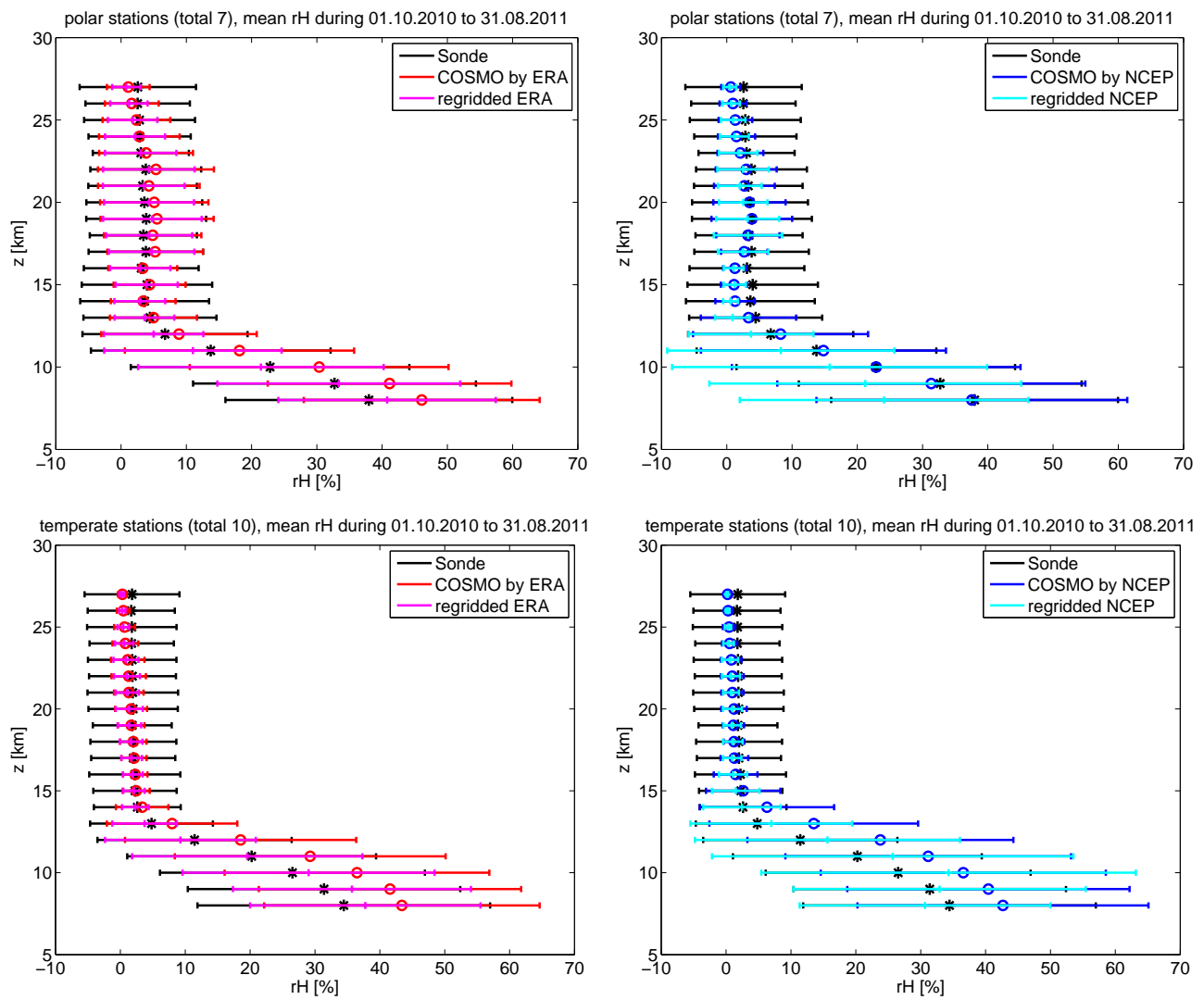

Figure 12. Mean values of relative humidity for polar (top) and temperate (bottom) stations for the model run forced by ERA-Interim (left) an NCEP (right) reanalysis data. Russian stations were excluded from this analysis, as described in the text. The horizontal lines give the $1 \sigma$ standard deviation.

so large that the model cannot be expected to reproduce the exact values that were measured at a specific site.

\section{Sensitivity study}

\subsection{Boundary forcing interval}

This section describes the results of the two model runs that were performed with larger boundary forcing intervals of $12 \mathrm{~h}$ (called int12 in plots) and $24 \mathrm{~h}$ (int24) relative to the other runs with 6-hourly forcing (called int6). Both of these runs ran stably and the setups were used to simulate the same time period as the run with 6-hourly forcing.

In order to compare the three runs, Table $\mathrm{C} 1$ gives the correlation coefficients of model and measured temperature and relative humidity (excluding Russian stations) for all three runs, listed separately for polar and temperate stations. The correlation is slightly weaker for both variables with the increased boundary forcing interval, the coefficient becoming smaller as the interval increases. This is expected, as the forcing interval determines how strongly the model is influenced by the boundary values that represent a realistic meteorology. But the decrease is not very strong and measured temperature can still be seen as very well reproduced even by the run that uses only one boundary input field per day.

In addition to comparing each run with measurement data, the runs can be directly compared with one another. For this, the 6-hourly time series data that was prepared at each station presents a good database. The difference between the model runs does not increase with simulation time (not shown). The mean difference between the separate stations and a mean of all stations in each height is presented in Fig. 17. In all heights and for both variables, the run with 24-hourly forcing shows a larger difference to the original run than the run with 12-hourly forcing.

\subsection{Extending the damping layer}

In a second test, the sensitivity of the model to the extent of the damping layer was investigated with an additional model run. For this run, the lower end of the damping layer was set to $22 \mathrm{~km}$ (called rdh22 in plots), $6 \mathrm{~km}$ lower than in the original run ( $\mathrm{rdh} 28)$. It then extends one-third of total model height of $33 \mathrm{~km}$.

Another test run had been planned for which the model height was increased to $42 \mathrm{~km}$, leaving the damping layer as is. This setup ran only for a few days before numerical insta- 

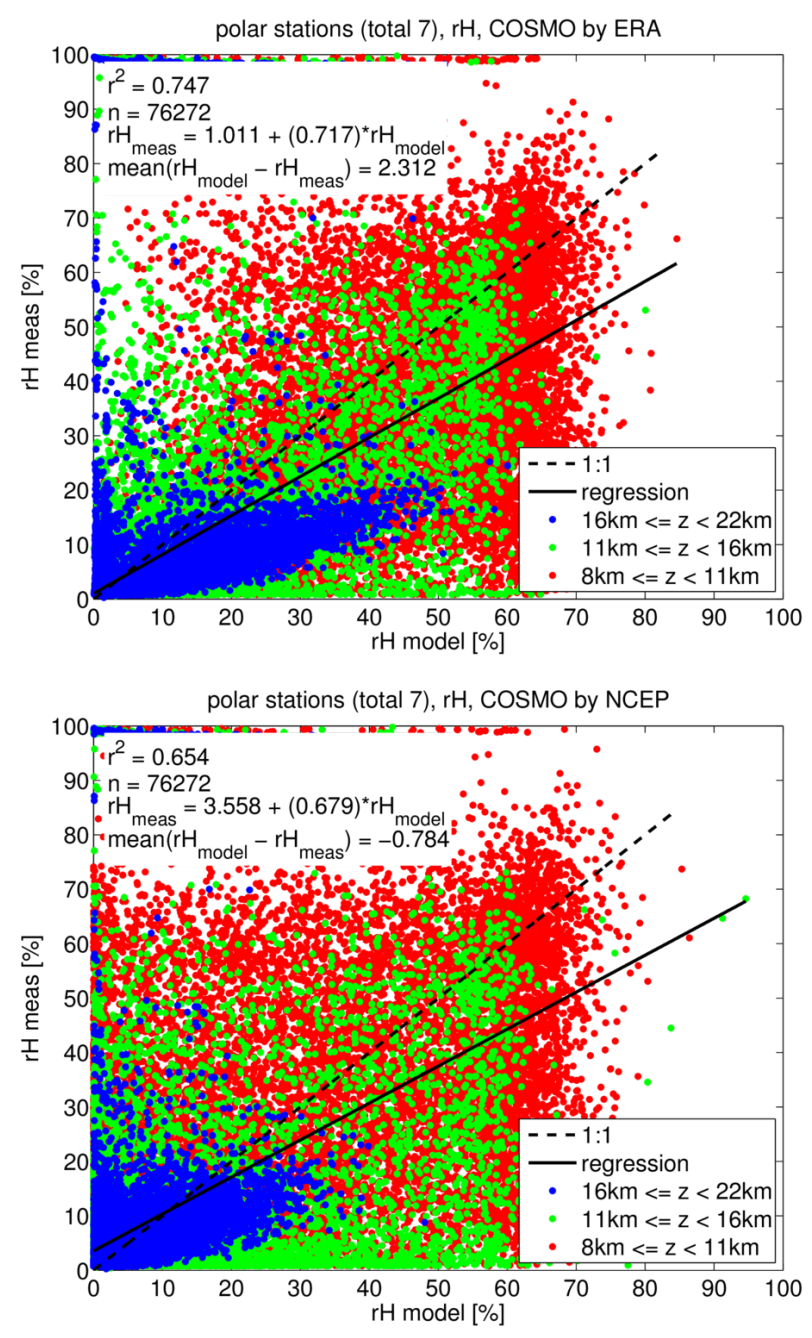

Figure 13. Scatterplots of modeled against measured relative humidity for the runs forced by ERA-Interim (top) and NCEP (bottom). The data were color coded by height to visually inspect the variability in each height section. The statistics in the upper left hand corner refer to the whole data set.

bilities lead to the breakdown of the model. The reasons for these instabilities were not investigated further, but this also showcases that it is not a trivial task to find a vertical grid with which the model runs stably.

The setup with rdheight $=22.0$ on the other hand ran stably for the time period considered in this study. Table C2 lists the correlation coefficient of model against measurement data for temperate and polar stations, including all layers up to $21 \mathrm{~km}$. The differences are only marginally small and the runs can be considered to reproduce measurements equally well.

In order to asses the difference between the model runs, the 6-hourly data generated for each station are again used to calculate a profile of the difference of the two model runs for each station and for the whole data set. The result of the analysis is shown in Fig. 18. The shapes of the curves are
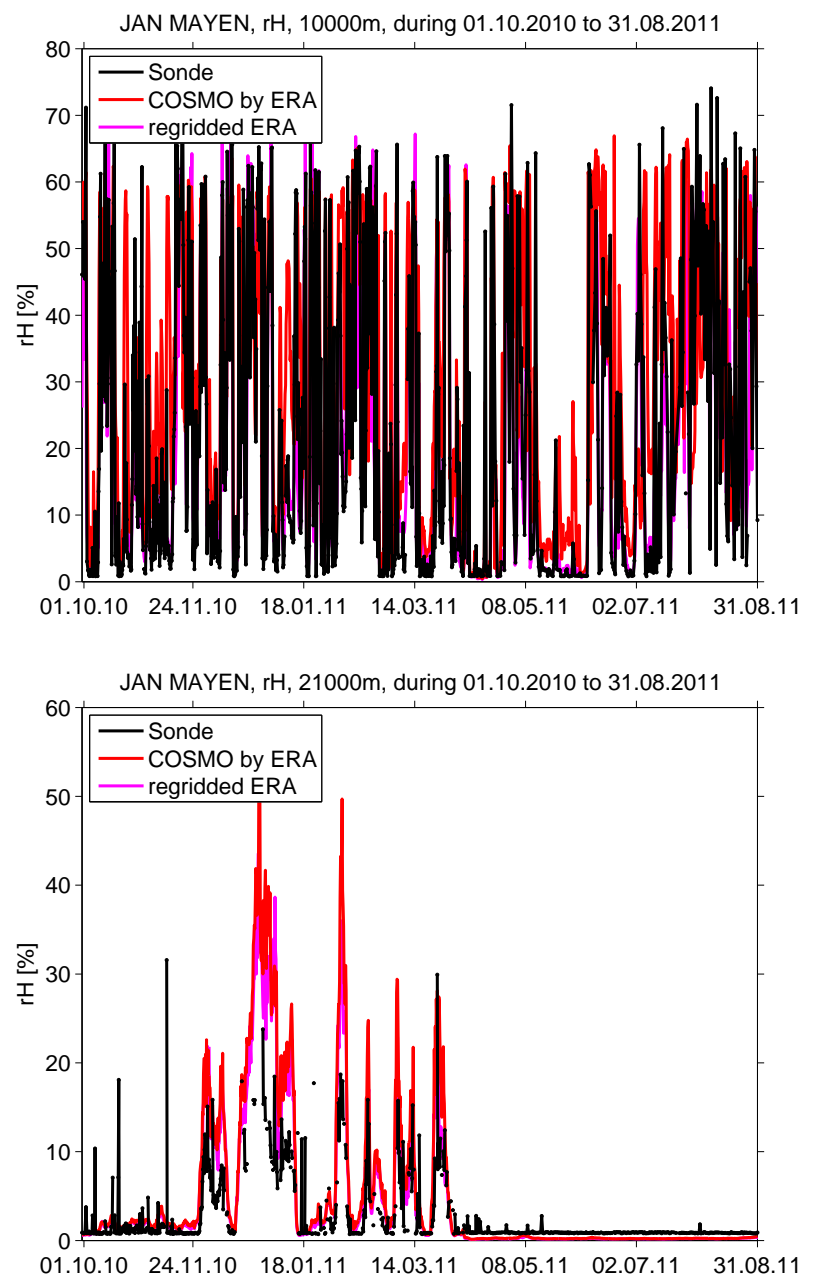

Figure 14. Time series of relative humidity at $10 \mathrm{~km}$ (top) and $21 \mathrm{~km}$ (bottom) height above Jan Mayen for the model forced by ERA-Interim data.

similar to those of Fig. 17, where the boundary input interval was varied. The overall difference is small and similar in magnitude to the difference when doubling the boundary forcing interval to $12 \mathrm{~h}$. Just where the damping layer starts to be active, a kink is visible in the profile of $T$, showing the necessity to stop evaluation of the model below the damping layer height when wanting to compare measurements and the model.

\section{Summary and conclusions}

This study presents a new, extended vertical grid for the regional model COSMO. The extended grid reaches up to $33 \mathrm{~km}$, almost $10 \mathrm{~km}$ above the model top of the standard vertical setup used for the forecast of central Europe by the DWD in the domain COSMO-DE. By reducing the magnitude of the damping layer to $5 \mathrm{~km}$, the added layer that can be considered to be free running reaches $28 \mathrm{~km}$, compared 
Meas-COSMO by ERA, 01.10 .10 to 31.08 .11 , all levels
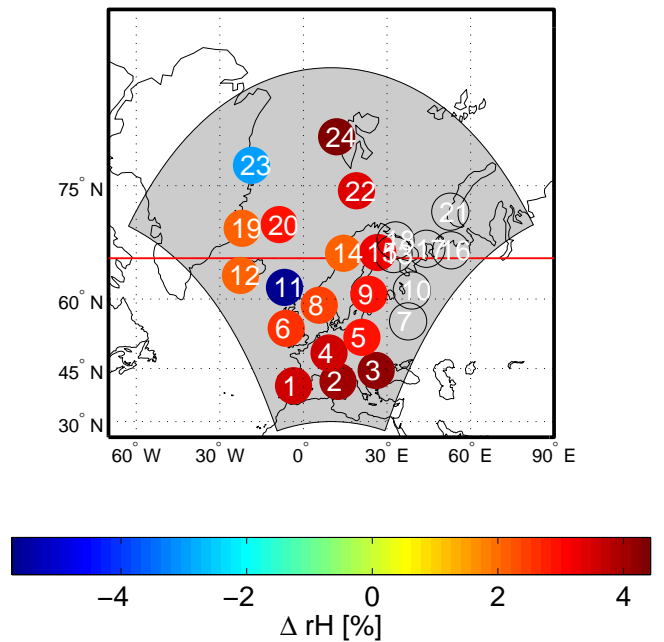

Figure 15. Mean difference of measurements and model values of relative humidity for each station when using ERA-Interim as forcing data. The picture is similar when using NCEP reanalysis data.

to $11 \mathrm{~km}$ in the standard setup. This is already well in the lowermost stratosphere.

The extended vertical grid is planned to be used for simulations covering the polar spring and the associated ozone loss, which is why it was tested using a domain spreading over central and northern Europe. To assess the influence of different boundary conditions, two model runs were compared with measurements, using ERA-Interim or NCEP reanalysis as boundary conditions for the model. Both model runs covered the same period, from 1 October 2010 to 1 September 2011. The model simulated this period stably. Additionally, three more runs using ERA-Interim as boundary forcing were done, two with increased boundary forcing intervals of 12 and $24 \mathrm{~h}$ and one with an increased damping reaching down to $22 \mathrm{~km}$.

The output was compared with measurements of temperature and relative humidity from all 12 polar radiosonde stations in the domain and as many in temperate latitudes.

The measurements of temperatures are well reproduced by the model for all stations and heights. This is not only true for the mean, but also for the comparison of single ascents. The error in heights above $11 \mathrm{~km}$ is even smaller than that when considering all layers, probably because the variability is not as high as when including the tropospheric values. The mean error made by the model is smaller than $0.5 \mathrm{~K}$ for all stations. The boundary data, which was regridded to the output grid, reaches similar values.

When comparing relative humidity values, it was found that Russian stations (and Gomel in Belarus) had systematically submitted higher values. This finding was strengthened by comparing all 23 Russian stations in the domain and Gomel to 24 stations not in Russia but in the eastern part of
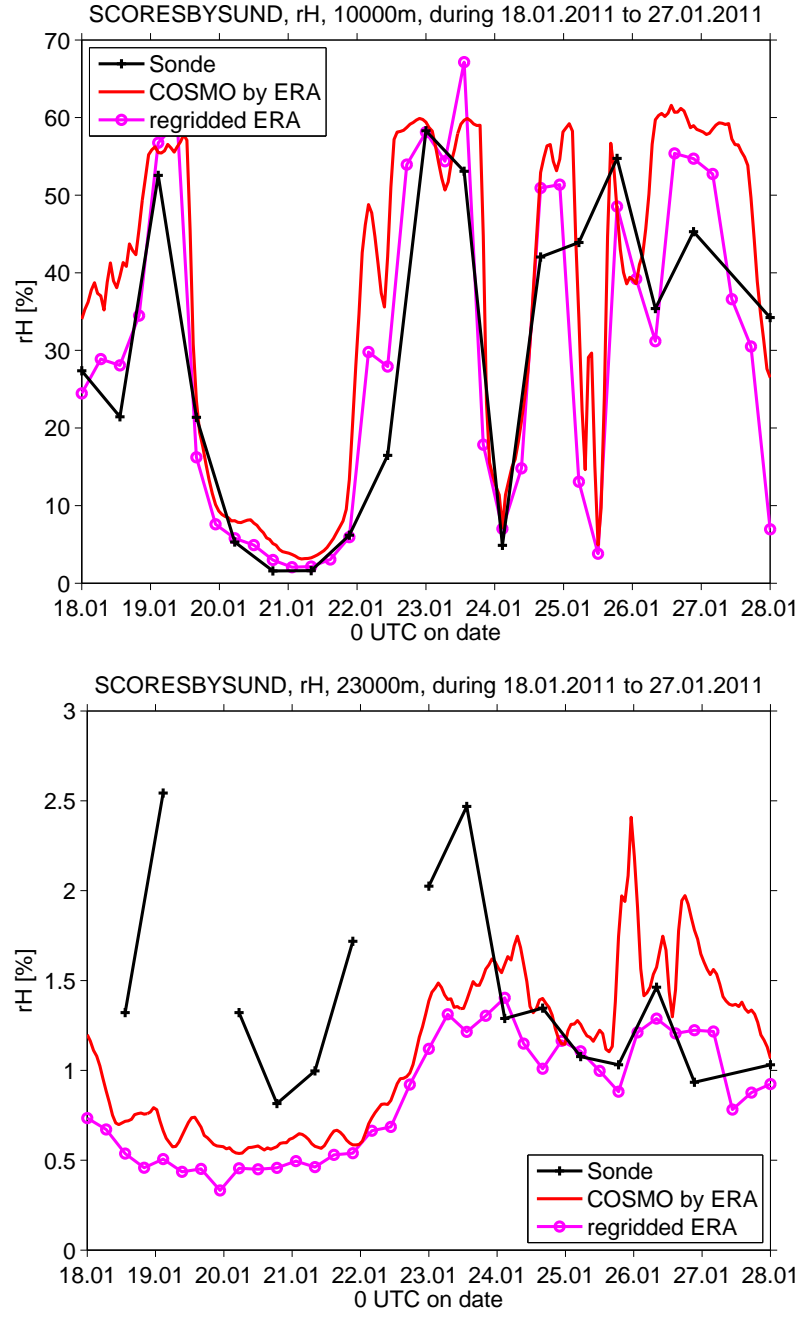

Figure 16. Time series of relative humidity at 10 (top) and $23 \mathrm{~km}$ (bottom) heights above Scoresbysund for the model, the forcing ERA-Interim reanalysis and the measurement data at the end of January 2011.

the domain and considering model and boundary data. After excluding Russian stations from the analysis of relative humidity, it became apparent that the model is not capable of reproducing the exact values of each measurement and neither is the regridded boundary data. But it does reproduce the low stratospheric values and fits measurements well when taking a mean over the whole time period. In the tropospheric layers, the model values are more humid than measurements.

The sensitivity study using longer boundary forcing intervals shows how the model reacts to this factor. The difference to measurements increases with increasing the interval, just like the difference to the original model run. The stability of the model when using the extended vertical layering does not depend on short boundary forcing intervals. The results of the run with an increased damping layer height reaching down to $22 \mathrm{~km}$ do not differ much from the original setup. 

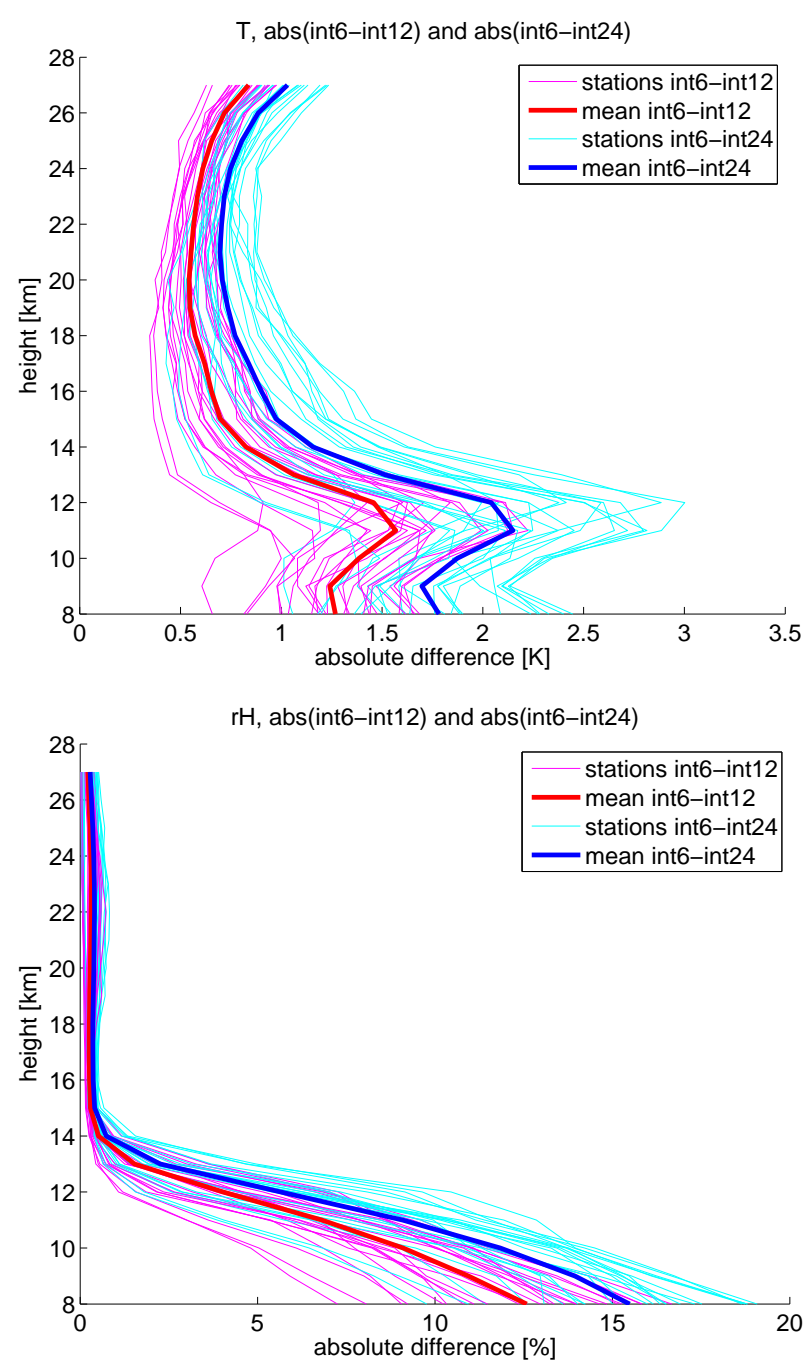

Figure 17. Difference between the model runs with 12 and 24hourly forcing to the original run with 6-hourly forcing for $T$ (top) and RH (bottom). Shown is one profile for each station and the mean of all stations.

The height of the damping layer does influence the results of the model, but differences reach only about $1 \mathrm{~K}$ to the case of $T$, for example.

The vertical grid for COSMO presented in this study seems a good alternative to the standard vertical layering of the COSMO-DE domain when focusing on the upper troposphere and lower stratosphere in polar latitudes. It has been shown to run stably, simulating almost a year. By comparing with data from synoptic radiosondes and regridded reanalysis data, it could be shown that the model is able to reproduce measurements of temperature well and produce reasonable values of relative humidity. The enlarged time series show a small-scale variability in the model that is not present in the measurements and cannot be expected form regridding the boundary data. The stability against varying the boundary forcing interval and the extent of the damping layer was
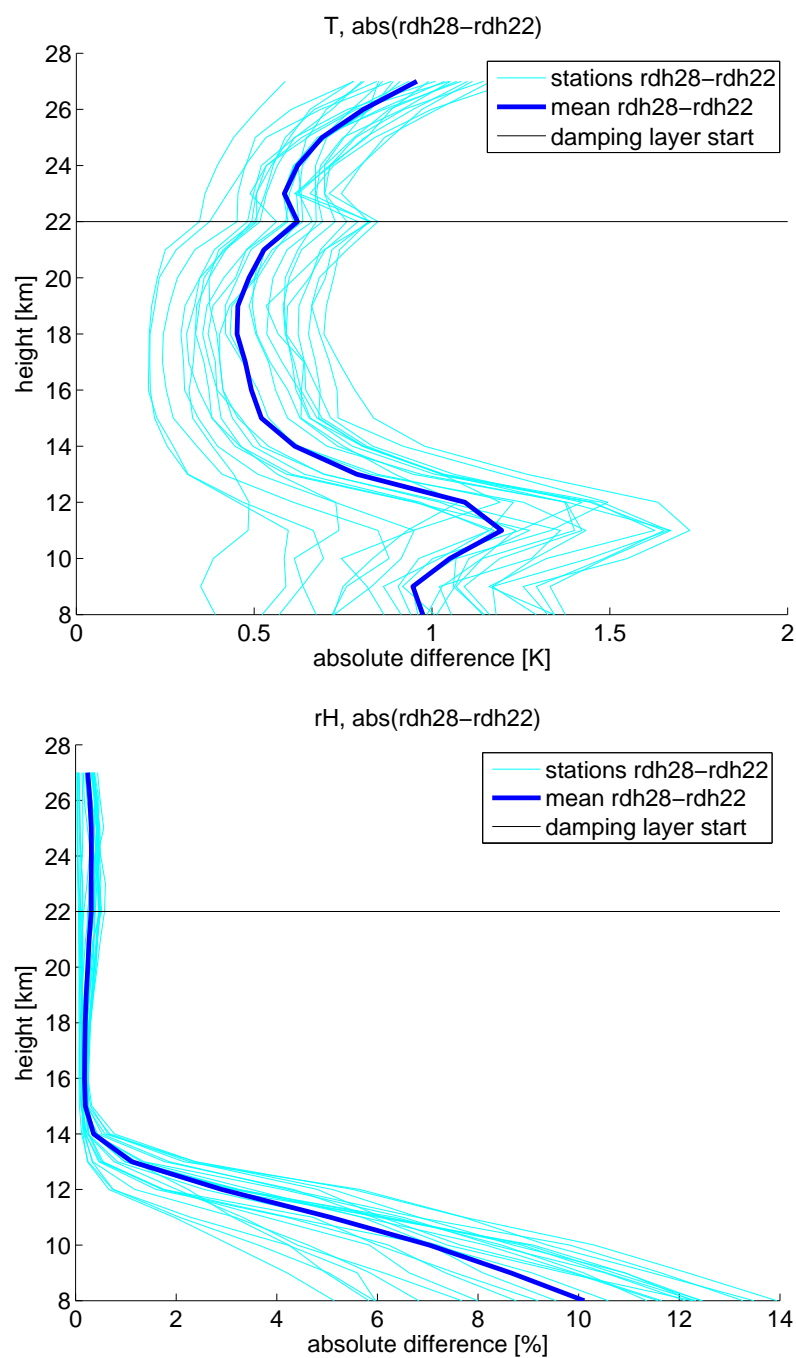

Figure 18. Difference between the model run with the lowest extent of the damping layer at $28 \mathrm{~km}$ to the standard with rdheight $=22$ for $T$ (top) and RH (bottom). Shown is one profile for each station and the mean of all stations.

shown with three additional model runs. Using this extended vertical grid expands the possible applications of COSMO into the stratosphere. With its high resolution it could be used to study cross-tropopause transport or simulate the chemistry of the lower stratosphere in polar latitudes when also including COSMO-ART. 


\section{Appendix A: Model specifications}

This appendix specifies the model setup. It gives the namelist settings for the preprocessor int $2 \mathrm{~lm}$ needed to reproduce the geographic model domain in Table A2 and the exact values of the vertical grids - the new, extended grid as well as the standard grid used for COSMO-DE - in Table A1.

Table A1. Heights of the layers of the standard and the extended COSMO grid, specified in meters.

\begin{tabular}{|c|c|c|c|c|c|}
\hline No. & Extended & Standard & No. & Extended & Standard \\
\hline 0 & 0.00 & 0.00 & 31 & 8711.53 & 7539.64 \\
\hline 1 & 70.00 & 20.00 & 32 & 9255.31 & 8080.00 \\
\hline 2 & 151.86 & 51.43 & 33 & 9818.03 & 8642.86 \\
\hline 3 & 245.82 & 94.64 & 34 & 10399.91 & 9228.57 \\
\hline 4 & 352.10 & 150.00 & 35 & 11001.17 & 9837.50 \\
\hline 5 & 470.92 & 217.86 & 36 & 11622.05 & 10470.00 \\
\hline 6 & 602.52 & 298.57 & 37 & 12262.76 & 11126.43 \\
\hline 7 & 747.13 & 392.50 & 38 & 12923.55 & 11807.14 \\
\hline 8 & 904.97 & 500.00 & 39 & 13604.64 & 12512.50 \\
\hline 9 & 1076.27 & 621.43 & 40 & 14306.25 & 13242.86 \\
\hline 10 & 1261.25 & 757.14 & 41 & 15028.62 & 13998.57 \\
\hline 11 & 1460.15 & 907.50 & 42 & 15771.97 & 14780.00 \\
\hline 12 & 1673.20 & 1072.28 & 43 & 16536.53 & 15587.50 \\
\hline 13 & 1900.61 & 1253.57 & 44 & 17322.52 & 16421.43 \\
\hline 14 & 2142.63 & 1450.00 & 45 & 18130.19 & 17282.14 \\
\hline 15 & 2399.47 & 1662.50 & 46 & 18959.74 & 18170.00 \\
\hline 16 & 2671.37 & 1891.43 & 47 & 19811.42 & 19085.36 \\
\hline 17 & 2958.56 & 2137.14 & 48 & 20685.45 & 20028.57 \\
\hline 18 & 3261.25 & 2400.00 & 49 & 21582.05 & 21000.00 \\
\hline 19 & 3579.68 & 2680.36 & 50 & 22501.46 & 22000.00 \\
\hline 20 & 3914.09 & 2978.57 & 51 & 23443.90 & - \\
\hline 21 & 4264.68 & 3295.00 & 52 & 24409.61 & - \\
\hline 22 & 4631.70 & 3630.00 & 53 & 25398.80 & _- \\
\hline 23 & 5015.37 & 3983.93 & 54 & 26411.71 & - \\
\hline 24 & 5415.92 & 4357.14 & 55 & 27448.57 & - \\
\hline 25 & 5833.58 & 4750.00 & 56 & 28509.60 & - \\
\hline 26 & 6268.57 & 5162.86 & 57 & 29595.03 & - \\
\hline 27 & 6721.12 & 5596.07 & 58 & 30705.08 & - \\
\hline 28 & 7191.47 & 6050.00 & 59 & 31840.00 & - \\
\hline 29 & 7679.83 & 6525.00 & 60 & 33000.00 & - \\
\hline 30 & 8186.44 & 7021.43 & - & - & - \\
\hline
\end{tabular}

Table A2. Name list parameters of the preprocessor int $21 \mathrm{~m}$ needed to reproduce the model domain.

\begin{tabular}{llr}
\hline Name list block & Parameter & Value \\
\hline LMGRID & ivctype & 2 \\
& irefatm & 2 \\
& lnewVGrid & .TRUE. \\
& ielm_tot & 190 \\
& jelm_tot & 255 \\
& kelm_tot & 60 \\
& pollat & 30.0 \\
& pollon & -170.0 \\
& polgam & 0.0 \\
& dlon & 0.2 \\
& dlat & 0.2 \\
& startlat_tot & -29.0 \\
& startlon_tot & -19.0 \\
& vcflat & 18000.0 \\
\hline DATA & ie_ext & 200 \\
& je_ext & 265 \\
\hline
\end{tabular}




\section{Appendix B: Specifications of the stations}

This appendix specifies the stations from which data were used in this study. Table B1 lists the information for those stations used for the original study, while Tables B2 and B3 list the information of the 48 stations that were used to investigate the bias in relative humidity of the stations in Russia.

Table B1. Specifications of the stations from which data were used in this study. Stations 1-12 are in temperate latitudes, 13-24 in polar latitudes. The international country code is also given. Real coordinates are those of the true location, model coordinates those of the closest grid point used to compare measurements and model data.

\begin{tabular}{lllrrrrrr}
\hline No. & Name & Country & WMO no. & Lat real & Lat model & Long real & Long model & Ascents \\
\hline 1 & Madrid & ES & 08221 & 40.470 & 40.494 & -3.580 & -3.521 & 654 \\
2 & Pratica di Mare & IT & 16245 & 41.650 & 41.562 & 12.430 & 12.537 & 995 \\
3 & Bucharest & RO & 15420 & 44.500 & 44.554 & 26.130 & 26.168 & 670 \\
4 & Stuttgart & DE & 10739 & 48.830 & 48.796 & 9.200 & 9.107 & 674 \\
5 & Legionowo & PL & 12374 & 52.400 & 52.428 & 20.970 & 21.112 & 671 \\
6 & Castor Bay & IE & 03918 & 54.300 & 54.247 & -6.190 & -6.178 & 495 \\
7 & Moscow & RU & 27612 & 55.750 & 55.859 & 37.570 & 37.458 & 633 \\
8 & Stavanger & SE & 01415 & 58.870 & 58.929 & 5.670 & 5.735 & 623 \\
9 & Jokioinen & FI & 02963 & 60.820 & 60.721 & 23.500 & 23.588 & 652 \\
10 & Kargopol & RU & 22845 & 61.500 & 61.441 & 38.930 & 38.903 & 593 \\
11 & Tórshavnar & DK & 06011 & 62.020 & 62.007 & -6.770 & -6.783 & 651 \\
12 & Keflavik & IS & 04018 & 63.970 & 63.951 & -22.600 & -22.593 & 649 \\
\hline 13 & Kandalaksha & RU & 22217 & 67.150 & 67.136 & 32.350 & 32.366 & 670 \\
14 & Bodo Vi & NO & 01152 & 67.250 & 67.137 & 14.400 & 14.601 & 651 \\
15 & Sodankylä & FI & 02836 & 67.370 & 67.390 & 26.650 & 26.677 & 663 \\
16 & Naryan Mar & RU & 23205 & 67.650 & 67.662 & 53.020 & 52.948 & 636 \\
17 & Sojna & RU & 22271 & 67.880 & 67.946 & 44.130 & 44.126 & 650 \\
18 & Murmansk & RU & 22113 & 68.970 & 68.963 & 33.050 & 33.004 & 672 \\
19 & Scoresbysund & GL & 04339 & 70.480 & 70.642 & -21.970 & -22.020 & 657 \\
20 & Jan Mayen & NO & 01001 & 70.930 & 70.911 & -8.670 & -8.860 & 1040 \\
21 & Malye Karmakuly & RU & 20744 & 72.380 & 72.285 & 52.730 & 52.609 & 591 \\
22 & Bjørnøya & NO & 01028 & 74.520 & 74.640 & 19.020 & 18.792 & 986 \\
23 & Danmarkshavn & GL & 04320 & 76.770 & 76.759 & -18.670 & -18.470 & 644 \\
24 & Ny-Ålesund & NO & 01004 & 78.920 & 78.994 & 11.930 & 11.981 & 352 \\
\hline & & & & & & & &
\end{tabular}


Table B2. Specifications of the Russian stations from which data were used in this study, listed from south to north. Real coordinates are those of the true location, model coordinates those of the closest grid point used to compare measurements and model data.

\begin{tabular}{lllrrrrrr}
\hline No. & Name & Country & WMO no. & Lat real & Lat model & Long real & Long model & Ascents \\
\hline 1 & Voronez & RU & 34122 & 51.670 & 51.608 & 39.270 & 39.392 & 640 \\
2 & Kursk & RU & 34009 & 51.770 & 51.865 & 36.170 & 36.056 & 603 \\
3 & Gomel & $\mathrm{BY}$ & 33041 & 52.450 & 52.595 & 31.000 & 30.948 & 468 \\
4 & Suhinici & $\mathrm{RU}$ & 27707 & 54.120 & 53.983 & 35.330 & 35.341 & 587 \\
5 & Ryazan & $\mathrm{RU}$ & 27730 & 54.630 & 54.651 & 39.700 & 39.578 & 668 \\
6 & Kaliningrad & $\mathrm{RU}$ & 26702 & 54.700 & 54.696 & 20.620 & 20.733 & 442 \\
7 & Smolensk & $\mathrm{RU}$ & 26781 & 54.750 & 54.680 & 32.070 & 32.131 & 671 \\
8 & Moscow & $\mathrm{RU}$ & 27612 & 55.750 & 55.859 & 37.570 & 37.458 & 633 \\
9 & Nizhny Novgorod & $\mathrm{RU}$ & 27459 & 56.270 & 56.330 & 44.000 & 43.869 & 654 \\
10 & Velikie Luki & $\mathrm{RU}$ & 26477 & 56.380 & 56.450 & 30.600 & 30.566 & 649 \\
11 & Bologoye & $\mathrm{RU}$ & 26298 & 57.900 & 57.877 & 34.050 & 34.220 & 639 \\
12 & Vologda & $\mathrm{RU}$ & 27037 & 59.230 & 59.217 & 39.870 & 39.908 & 300 \\
13 & St. Petersburg & $\mathrm{RU}$ & 26063 & 59.970 & 60.054 & 30.300 & 30.348 & 656 \\
14 & Kargopol & $\mathrm{RU}$ & 22845 & 61.500 & 61.441 & 38.930 & 38.903 & 593 \\
15 & Syktyvkar & $\mathrm{RU}$ & 23804 & 61.720 & 61.672 & 50.830 & 50.748 & 668 \\
16 & Petrozavodsk & $\mathrm{RU}$ & 22820 & 61.820 & 61.926 & 34.270 & 34.313 & 666 \\
17 & Arhangelsk & $\mathrm{RU}$ & 22550 & 64.530 & 64.405 & 40.580 & 40.568 & 296 \\
18 & Kem & $\mathrm{RU}$ & 22522 & 64.980 & 65.083 & 34.800 & 34.658 & 645 \\
19 & Pecora & $\mathrm{RU}$ & 23418 & 65.120 & 65.044 & 57.100 & 57.081 & 670 \\
20 & Kandalaksha & $\mathrm{RU}$ & 22217 & 67.150 & 67.136 & 32.350 & 32.366 & 670 \\
21 & Naryan Mar & $\mathrm{RU}$ & 23205 & 67.650 & 67.662 & 53.020 & 52.948 & 636 \\
22 & Sojna & $\mathrm{RU}$ & 22271 & 67.880 & 67.946 & 44.130 & 44.126 & 650 \\
23 & Murmansk & $\mathrm{RU}$ & 22113 & 68.970 & 68.963 & 33.050 & 33.004 & 672 \\
24 & Malye Karmakuly & $\mathrm{RU}$ & 20744 & 72.380 & 72.285 & 52.730 & 52.609 & 589 \\
\hline
\end{tabular}

Table B3. Same as Table B2 but for those stations outside of Russia used to compare to those in Russia.

\begin{tabular}{lllrrrrrr}
\hline No. & Name & Country & WMO no. & Lat real & Lat model & Long real & Long model & Ascents \\
\hline 1 & Bucharest & RO & 15420 & 44.500 & 44.554 & 26.130 & 26.168 & 670 \\
2 & Cluj Napoca & RO & 15120 & 46.780 & 46.839 & 23.570 & 23.496 & 336 \\
3 & Poprad & PL & 11952 & 49.030 & 49.073 & 20.320 & 20.240 & 672 \\
4 & Prostejov & PL & 11747 & 49.450 & 49.337 & 17.130 & 17.256 & 656 \\
5 & Prague & CZ & 11520 & 50.000 & 49.896 & 14.450 & 14.589 & 1341 \\
6 & Wroclaw & PL & 12425 & 51.130 & 51.169 & 16.980 & 16.949 & 668 \\
7 & Lin & DE & 10393 & 52.220 & 52.118 & 14.120 & 14.197 & 1348 \\
8 & Legionowo & PL & 12374 & 52.400 & 52.428 & 20.970 & 21.112 & 671 \\
9 & Greifswald & DE & 10184 & 54.100 & 54.149 & 13.400 & 13.399 & 668 \\
10 & Schleswig & DE & 10035 & 54.530 & 54.599 & 9.550 & 9.656 & 671 \\
11 & Leba & PL & 12120 & 54.750 & 54.747 & 17.530 & 17.609 & 667 \\
12 & Kaunas & LT & 26629 & 54.880 & 54.757 & 23.880 & 23.914 & 336 \\
13 & Visby & SE & 02591 & 57.650 & 57.725 & 18.350 & 18.255 & 594 \\
14 & Gothenburg & SE & 02527 & 57.670 & 57.580 & 12.300 & 12.237 & 331 \\
15 & Stavanger & NO & 01415 & 58.870 & 58.929 & 5.670 & 5.735 & 623 \\
16 & Tallinn & EE & 26038 & 59.450 & 59.574 & 24.800 & 24.733 & 333 \\
17 & Jokioinen & FI & 02963 & 60.820 & 60.721 & 23.500 & 23.588 & 652 \\
18 & Jyväskylä & FI & 02935 & 62.400 & 62.346 & 25.670 & 25.642 & 670 \\
19 & Sundsvall & SE & 02365 & 62.530 & 62.610 & 17.470 & 17.398 & 598 \\
20 & Ørland & NO & 01241 & 63.700 & 63.599 & 9.600 & 9.551 & 667 \\
21 & Luleå & SE & 02185 & 65.550 & 65.542 & 22.130 & 22.085 & 331 \\
22 & Bodo Vi & NO & 01152 & 67.250 & 67.137 & 14.400 & 14.601 & 638 \\
23 & Sodankylä & FI & 02836 & 67.370 & 67.390 & 26.650 & 26.677 & 663 \\
24 & Bjørnøya & NO & 01028 & 74.520 & 74.640 & 19.020 & 18.792 & 986 \\
\hline
\end{tabular}




\section{Appendix C}

Table C1. Correlation coefficients for the three model runs forced by ERA-Interim against measurements, using 6-, 12- or 24-hourly boundary forcing for polar and temperate stations and both variables, $T$ and $\mathrm{RH}$.

\begin{tabular}{lrrr|rrr}
\hline & \multicolumn{3}{c|}{ Temperate } & \multicolumn{3}{c}{ Polar } \\
\cline { 2 - 7 } Forcing & \multirow{2}{*}{12} & 24 & 6 & 12 & 24 \\
interval & 6 & 0.957 & 0.946 & 0.982 & 0.979 & 0.973 \\
\hline$T$ & 0.961 & 0.973 & & \\
RH & 0.754 & 0.740 & 0.707 & 0.747 & 0.735 & 0.706 \\
\hline
\end{tabular}

Table C2. Correlation coefficients for the two model runs forced by ERA-Interim against measurements, using 28 or $22 \mathrm{~km}$ as lowest extents of the damping layer for polar and temperate stations and both variables, $T$ and $\mathrm{RH}$.

\begin{tabular}{lrr|rr}
\hline & \multicolumn{2}{c|}{ Temperate } & \multicolumn{2}{c}{ Polar } \\
\cline { 2 - 5 } Damp. height & 28 & 22 & 28 & 22 \\
\hline$T$ & 0.961 & 0.962 & 0.982 & 0.982 \\
RH & 0.754 & 0.758 & 0.747 & 0.747 \\
\hline
\end{tabular}


Acknowledgements. We acknowledge support by Deutsche Forschungsgemeinschaft and Open Access Publishing Fund of Karlsruhe Institute of Technology.

The article processing charges for this open-access publication were covered by a Research

Centre of the Helmholtz Association.

Edited by: A. Kerkweg

\section{References}

Balagurov, A., Kats, A., Krestyannikova, N., and Schmidlin, F.: WMO Radiosonde humidity sensor intercomparison, Instruments and observing methods report No. 85 WMO/TD-No. 1305, WMO, Geneva, Switzerland, 2006.

Baldauf, M., Förstner, J. F., Klink, S., Reinhardt, T., Schraff, C., Seifert, A., and Stephan, K.: Kurze Beschreibung des LokalModells Kürzestfrist COSMO-DE (LMK) und seiner Datenbanken auf dem Datenserver des DWD, Tech. rep., DWD, Offenbach, Germany, 2011a.

Baldauf, M., Seifert, A., Förstner, J., Majewski, D., Raschendorfer, M., and Reinhardt, T.: Operational convective-scale numerical weather prediction with the COSMO model: description and sensitivities, Mon. Weather Rev., 139, 3887-3905, 2011 b.

Dee, D. P., Uppala, S. M., Simmons, A. J., Berrisford, P., Poli, P., Kobayashi, S., Andrae, U., Balmaseda, M. A., Balsamo, G., Bauer, P., Bechtold, P., Beljaars, A. C. M., van de Berg, L., Bidlot, J., Bormann, N., Delsol, C., Dragani, R., Fuentes, M., Geer, A. J., Haimberger, L., Healy, S. B., Hersbach, H., Hólm, E. V., Isaksen, L., Kållberg, P., Köhler, M., Matricardi, M., McNally, A. P., Monge-Sanz, B. M., Morcrette, J.-J., Park, B.-K., Peubey, C., de Rosnay, P., Tavolato, C., Thépaut, J.-N., and Vitart, F.: The ERA-Interim reanalysis: configuration and performance of the data assimilation system, Q. J. Roy. Meteorol. Soc., 137, 553597, doi:10.1002/qj.828, 2011.

Gantner, L. and Kalthoff, N.: Sensitivity of a modelled life cycle of a mesoscale convective system to soil conditions over West Africa, Q. J. Roy. Meteorol. Soc., 136, 471-482, doi:10.1002/qj.425, 2010.
Kalnay, E., Kanamitsu, M., Kistler, R., Collins, W., Deaven, D., Gandin, L., Iredell, M., Saha, S., White, G., Woollen, J., Zhu, Y., Leetmaa, A., Reynolds, R., Chelliah, M., Ebisuzaki, W., Higgins, W., Janowiak, J., Mo, K. C., Ropelewski, C., Wang, J., Jenne, R., and Joseph, D.: The NCEP/NCAR 40-Year Reanalysis Project, B. Am. Meteorol. Soc., 77, 437-471, 1996.

Krähenmann, S., Kothe, S., Panitz, H.-J., and Ahrens, B.: Evaluation of daily maximum and minimum 2-m temperatures as simulated with the Regional Climate Model COSMO-CLM over Africa, Meteorol. Z., 22, 297-316, doi:10.1127/09412948/2013/0468, 2013.

Moradi, I., Soden, B., Ferraro, R., Arkin, P., and Vömel, H.: Assessing the quality of humidity measurements from global operational radiosonde sensors, J. Geophys. Res.-Atmos., 118, 8040 8053, doi:10.1002/jgrd.50589, 2013.

Schättler, U.: A Description of the Nonhydrostatic Regional COSMO-Model Part V: Preprocessing: Initial and Boundary Data for the COSMO-Model, Tech. rep., DWD, Offenbach, Germany, 2013.

Schulz, J.-P. and Schättler, U.: Kurze Beschreibung des LokalModells Europa COSMO-EU (LME) und seiner Datenbanken auf dem Datenserver des DWD, Tech. rep., DWD, Offenbach, Germany, 2009.

Schwartz, B. and Govett, M.: A Hydrostatically Consistent North American Radiosonde Data Base At The Forecast Systems Laboratory, 1946-Present, Tech. rep., NOAA, Forecast Systems Laboratory, Boulder, USA, 1992.

Sissenwine, N., Dubin, M., and Wexler, H.: The U.S. Standard Atmosphere, 1962, J. Geophys. Res., 67, 3627-3630, doi:10.1029/JZ067i009p03627, 1962.

Vogel, B., Vogel, H., Bäumer, D., Bangert, M., Lundgren, K., Rinke, R., and Stanelle, T.: The comprehensive model system COSMOART - Radiative impact of aerosol on the state of the atmosphere on the regional scale, Atmos. Chem. Phys., 9, 8661-8680, doi:10.5194/acp-9-8661-2009, 2009.

Wang, J., Zhang, L., Dai, A., Immler, F., Sommer, M., and Vömel, H.: Radiation dry bias correction of Vaisala RS92 humidity data and its impacts on historical radiosonde data, J. Atmos. Ocean. Tech., 30, 197-214, 2013.

Zahn, A., Christner, E., van Velthoven, P. F. J., Rauthe-Schöch, A., and Brenninkmeijer, C. A. M.: Processes controlling water vapor in the upper troposphere/lowermost stratosphere: An analysis of 8 years of monthly measurements by the IAGOSCARIBIC observatory, J. Geophys. Res.-Atmos., 119, 1150511525, doi:10.1002/2014JD021687, 2014. 